\section{COIRÓN: DUREZA Y FRAGILIDAD}

\section{EDSON FAÚNDEZ V.}

Universidad de Concepción, Chile

efaundez@udec.cl

\title{
RESUMEN
}

Dos problemas aborda este artículo dedicado al estudio de Coirón (1951): la fascinación y el repudio ante «el placer inusitado de vivir» y la significación del tiempo y la memoria en la escritura novelesca de Daniel Belmar.

Palabras clave: narrativa chilena, deseo, muerte.

\section{ABSTRACT}

Two problems are dealt with in this article, dedicated to the study of Coirón (1951): the fascination with and the repudiation of «the uncommon pleasure of living» and the significance of time and memory in the novelistic writing of Daniel Belmar.

Keywords: chilean narrative, desire, death.

Para Pacián Martínez Elissetche

Aparecí, de repente, en un país negro, desolado; en un territorio sin fronteras, siniestro, flanqueado de brumas; una región extraña, violenta, erizada de riesgos. Detrás de mí, ningún recuerdo, ninguna sensación. Delante, la noche, la muerte.

Eché a andar por el obscuro páramo. Tropecé. Caí. Sin saber cómo me encontré huyendo. Corría, corría. Ciego, desatentado. Un impulso misterioso, una llamada obscura me impelía a huir.

(Daniel Belmar, Coirón)

\section{Deseo}

Coirón ${ }^{1}$ se construye sobre la base de dos territorios que polarizan el relato: el de la pampa, revelado con meticulosidad a partir de la presentación de su geografía física y humana, y la omnipresente patria (Chile), evocada con nostalgia por la madre: «cuando nos casamos, tu padre tenía un terrenito en Quino, cerca de Traiguén. Criaba ovejitas, sembraba..., había un manzanar. No necesitábamos más. Éramos felices. Pero un día yado por los gendarmes y los tinterillos. Tu padre no tenía escritura. Trató de oponerse. Y nos quemaron la casa...» (Belmar, 1953, p. $22)^{2}$. El proyecto de la madre de retornar a la tierra, donde conoció la felicidad, para liberar a su familia de los peligros de la pampa, implícito en la cita anterior, revela las disimetrías de las relaciones de poder, la servidumbre de la ley y las injusticias sociales que rigen no sólo el relato de las experiencias de una familia de inmigrantes chilenos en Neuquén,
Edson Faúndez V.

Doctor en Literatura Latinoamericana por la Universidad de Concepción, Chile. Sus áreas de investigación actuales son, fundamentalmente, lírica latinoamericana y novela realista española decimonónica. Ha publicado artículos en revistas especializadas de Chile, Argentina y España, y los libros, en calidad de autor o editor, Prohibido asomarse al interior. Antología de la poesía de Omar Lara (2009), La oscura casa encantada. La poesía de César Vallejo y Oliverio Girondo (2010), Guardo el signo y agradezco. Aproximaciones críticas a la obra de Gabriela Mistral (2011. Coeditor: Dieter Oelker Link). Es profesor asociado del Departamento de Español y Director del Programa de Doctorado en Literatura Latinoamericana de la Universidad de Concepción.

1

Novela escrita por Daniel Belmar en Concepción de Chile (febrero de 1946 - julio de 1947) y publicada por la empresa editora Zig-Zag en 1951. La recepción crítica de esta novela fue favorable, siendo galardonada con el Premio Atenea, el Premio de la Municipalidad de Santiago y el Premio Arte de la Municipalidad de Concepción. Completan la obra literaria del autor Roble Guacho (novela, 1948), Oleaje (novela, 1950), Ciudad Brumosa (novela, 1952), Desembocadura (relatos, 1953), Sonata (carta de una adolescente) (novela 1955), Los túneles morados (novela, 1961), Descenso (poema, 1962), Evocación de Temuco (crónica, 1962), Detrás de las máscaras (novela, 1966), Dónde nacen las turquesas (inconclusa) y Carta a mi hermano gemelo (inconclusa).

2

Todas las citas de Coirón, de ahora en adelante, irán acompañadas sólo con el número de página. 


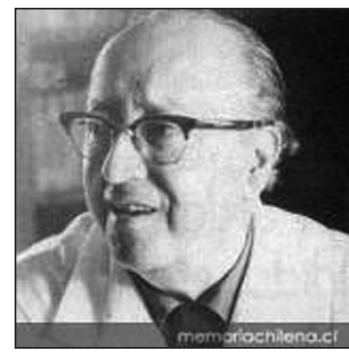

Daniel Belmar.

3

Pedro Henríquez Ureña comprende la imbricación entre novela y problemas sociales: "gran parte de la mejor literatura de la América hispánica expone hoy problemas sociales, o al menos describe situaciones que contienen en germen problemas. Normalmente es la novela el género que con más frecuencia apunto a estos aspectos de la sociedad en los tiempos modernos. En nuestra literatura aparecen tan pronto como nuestros novelistas pasan del romanticismo al realismo» (1954, p. 198).

Coirón: dureza y fragilidad EDSON FAÚNDEZ V. sino también el país que vivió y sufrió Daniel Belmar, quien considera que el escritor «es el historiador fidedigno de su tiempo. Nadie como él podría fijar con mayor fidelidad el sentido y contenido totales del momento que le corresponde vivir» (cit. en Martínez, 2009, p. 95). La novela puede considerarse así un discurso fictivo que, entre otras posibilidades, denuncia y resiste el ejercicio de los poderes hegemónicos ${ }^{3}$. Coirón se articula, pues, sobre un fondo que, entre otros aspectos, ilumina el mal que surge de los sectores política y económicamente dominantes: «el rico insolente» expulsa de Chile, apoyado por «los gendarmes y los tinterillos", a la familia de Rafael y «los gringos» compran la lana de las ovejas de los puesteros (gauchos e inmigrantes) a precio absurdo. La vinculación con las circunstancias socio-históricas que definen el contexto de producción de la novela permiten plantear con Elías Canetti que la escritura literaria de Belmar cumple a lo menos con dos de las exigencias básicas que habría que plantearle a un escritor: el compromiso con la época que le correspondió vivir y la resistencia feroz contra el mal que la gobierna. Hay un tercer rasgo que, unido al compromiso y la crítica, singulariza la obra de Belmar. Me refiero a la creación de lo que Bloch llama, en El principio esperanza (2004), ventanas utópicas. El sueño de la inversión de las relaciones de fuerza y, por consiguiente, el deseo de transformación social y construcción de un territorio hospitalario, se desliza por ellas. Los problemas que me instaron a releer la novela del escritor que se forjó en la brumosa ciudad de Concepción de Chile están inextricablemente relacionados con el imperativo ético y político de afectar la realidad.

Sarmiento, Alberdi, Lastarria, Bilbao, entre otros, recurrieron, en sus proyectos civilizadores, al binomio civilización-barbarie. Cifraron en la barbarie lo heredado, el mestizaje, la imposibilidad de movimiento y en lo civilizado lo ausente, lo fabricado en otro espacio, el objeto de una apropiación. Sarmiento, desde esta perspectiva de pensamiento, establece el compromiso literario-político que el escritor debe asumir para contribuir al perfeccionamiento de las repúblicas de nuestra América:

Poner ante los ojos del lector americano los elementos que constituyen nuestra sociedad; explicar el mal éxito parcial de las instituciones republicanas en tan grande extensión y en tan distintos ensayos por la resistencia de inercia que al fin desenvuelve calor en lo moral como en lo físico, señalar las deficiencias y apuntar los complementos, sin salir del cuadro que trazan a la América sus propios destinos (1993, p. 407).

Belmar adopta creativamente el proyecto de Sarmiento en la medida en que novelas como Coirón revelan «los elementos que constituyen nuestra sociedad» $\mathrm{y}$ «el mal éxito parcial de las instituciones republicanas». Él conoció y valoró el pensamiento de Sarmiento, por lo que es posible postular que en la novela, heredera del espacio textualizado en Martín Fierro y Don Segundo Sombra, se actualiza un diálogo intenso con el intelectual y estadista argentino. Así lo sugiere en clave cronística Pacián Martínez Elissetche:

Lo cierto es que Belmar citó siempre a Sarmiento como uno de los tantos extranjeros ilustres a quienes Chile debe aún grandes obras: Bello, Gay, Rugendas, Monvoisin, Rodulfo A. Philippi... [...] El aspecto que más impresionaba a Daniel Belmar de Sarmiento fue su amor por la educación, que lo llevó, siendo Gobernador y luego Presidente, a construir y fundar escuelas y centros especializados de enseñanza para técnicos agrícolas y mineros. Por eso lo comparaba con Balmaceda, otro de sus personajes históricos predilectos, de cuyo mandato sobreviven hasta hoy sólidos edificios donde estudiaron miles de niños que entregaron, más tarde, los conocimientos adquiridos en esos centros modelos a su patria. No olvido que Belmar mencionaba la Escuela Bulnes como uno de esos lugares y le preguntaba detalles a su amigo Rodolfo Gálvez Barrenechea, que con su natural erudición y cultura sin aspavientos, le entregaba los datos e informaciones que requería. $Y$ como era hermano de maestras, le entusiasmaba mucho el tema. Aparte de que Civilización y Barbarie le traía a la memoria Alaleicura y la salvaje presencia de la pampa que aparece en Coirón.

Es una lástima que Belmar no haya dejado, en papeles, su visión escrita de Sarmiento, debiendo conformarnos, los que fuimos sus cercanos, con los relatos orales (2009, p. 68-69).

«La abierta e infinita pampa», que invade la imaginación literaria de Belmar a partir de la experiencia familiar en Alaleicura y el conocimiento de la obra de Sarmiento, constituye un espacio liso, sin estratificaciones evidentes. El espacio de la pampa, sin límites, distribución, ni orden, se caracteriza por la suprema- 
cía del instinto. «El placer inusitado de vivir» (p. 68), que impone su dominio en la pampa, impide el despliegue de potencias distintas a las vinculadas con los apetitos de la carne, la violencia y la crueldad. La solidaridad y la piedad por ello han sido desterradas de las llanuras sin historia de la pampa:

La vida en las llanuras no tenía historia. Fechas, sucesos, acciones caían desmesurados en el constante y lento devenir. Se vivía sin esfuerzo, es verdad. Abundaba lo esencial. Pero faltaba la conexión directa del hombre con el hombre; el sentimiento de solidaridad sólo abarcaba el reducido núcleo de la familia. Un poco más allá y ya era el desprecio por la vida ajena. Era la lucha, no por la supervivencia, sino por la supremacía del instinto. Era el placer de matar por matar, a traición las más de las veces. Era, en fin, el hombre que regresaba al desenfreno, libre de trabas, perdiéndose en la impunidad de las grandes distancias. Era la vida fácil, pero alerta. Era Canaán, una Canaán erizada de puñales, en la que, para subsistir, había que ahogar el sentimiento, desterrar la piedad, endurecerse (p. 56).

Los actos de los hombres capturados por la pampa -gauchos e inmigrantes- expresan las consecuencias de la supremacía de lo instintivo. La violencia dirigida hacia el otro y la falta de contención de los instintos sexual y homicida acompañan dichos actos. Considérese, por ejemplo: «el monstruoso apareamiento, fornicando con ovejas y yeguas nuevas» (p. 34) y la violación de la anciana doña Carmen, deplorables proezas del Mocho; el comportamiento socialmente no encauzado de los Arriagada; el nomadismo de don Pedro, el domador; la promiscuidad de la joven esposa del gallego; la animalidad de José Bravo y el desenfreno sexual de su mujer; el enfrentamiento entre el toro y el puma, en el corral de Miranda, «espectáculo bárbaro, de un salvajismo impresionante y sobrecogedor» (p. 90); la solución del cuchillo; las borracheras colectivas; y el impulso cinegético. La bestialización de los personajes gobernados por las fuerzas de la pampa intensifica también la evaluación negativa de quienes desprecian la «vida ajena». Hombres-bestias recorren la árida y dura superficie donde transcurre la historia. Recuérdese, por ejemplo: «las dos pupilas de búho» (p. 46) del gallego Muerza; la concupiscencia de la mujer del gallego, que hace decir al narrador que «todos comían en el mismo plato, como los perros» (p. 48); o la escena en la que el Mocho, luego de la violación de doña Carmen, respira «entrecortadamente como zorro acosado» (p. 54). La efervescencia del instinto pareciera disolver los límites que separan los reinos, generando bodas monstruosas entre el hombre y el animal, las que generalmente desembocan en exceso y muerte.

Lo salvaje de los actos de los hombres dominados por el instinto se hace evidente y se amplifica a partir de la inclusión en el relato de una forma de vida antitética. Resulta de suma importancia, en este sentido, pensar la familia de inmigrantes chilenos como un dispositivo que une separando y separa uniendo el territorio de lo instintivo-bárbaro con el territorio de lo disciplinado-civilizado. La familia se posiciona así en una zona intermedia que permite distinguir el entrecruzamiento $\mathrm{y}$ las tensiones de las fuerzas en pugna, las cuales identificaré con la dureza (barbarie) y la fragilidad (civilización). La escena del gato que intenta cazar una golondrina, en el primer capítulo de la novela, parece simbolizar la continua lucha que enfrentará la familia, cuyo destino se debate entre la asimilación de los códigos de un territorio que es «una Canaán erizada de puñales» y la defensa de los códigos de un territorio en donde los poderes refractarios a la violencia y la crueldad se actualizan:

Había tal tensión, tal fuerza contenida en la traza del gato, que el espectáculo, pese a no ser nuevo para mí, volvió a aprisionarme en su extraña fascinación. El animal se arrastró algunos metros más. Se detuvo entonces, contrayéndose, inmovilizándose, fijas las crueles pupilas en las veloces golondrinas que cruzaban y recruzaban por sobre su cabeza en rápido vuelo rasante.

\section{Contuve la respiración.}

De súbito, como resorte soltado bruscamente, el cuerpo poderoso latigueó en el aire para atrapar la flecha obscura que venía, recta, a clavarse en las garras codiciosas. Pero la golondrina paró el vuelo en seco, como si hubiera chocado contra un muro invisible, y un giro vertiginoso la alejó del peligro mientras el felino caía ágilmente sobre sus cuatro patas.

Respiré aliviado (p. 27).

La escena del enfrentamiento del gato, cifra de las fuerzas de la dureza, y la golondrina, cifra de las fuerzas de la fragilidad, además de sugerir que la imagen del «muro invisible» se relaciona con el (auto)control de los movi-
Coirón: dureza y fragilidad EDSON FAÚNDEZ V. 
4

El lector de Coirón debe completar la imagen de los personajes a partir de la observación de sus acciones negativas $\circ$ positivas. Montes y Orlandi destacan este aspecto de la novela: «la tendencia paisajística, la inclinación a la acción, heredada probablemente de España, parecen ser obstáculo a la profundización psicológica. Los personajes quedan esbozados. De sus actuaciones debemos las más de las veces colegir sus reacciones íntimas.) (Montes y Orlandi, 1963, p. 227).

5

Gilberto Triviños, en unas notas inéditas dedicadas al examen de algunos rasgos de Coirón, advierte que la novela no puede reducirse al triunfo del deseo de la madre, pues el deseo de huir de la pampa termina siendo el deseo de toda la familia. Coirón, sostiene, es una novela regida por las imágenes familiares: padre, madre y hermanos.

6

La escena en la que los Arriagada retornan al puesto, luego de la expulsión del Mocho, muestra la preocupación de la madre ante las posibles consecuencias de la vida en la pampa: «En todos los ojos chispeó la confianza. Éramos jóvenes. La idea de la muerte se nos aparecía remota, confusa, inexistente, aun en medio de ese clima de violencia. La vida nos arrastraba en su corriente poderosa y pura. $Y$ nos dejábamos llevar, alegremente, sin inquietudes, sin torturarnos por el terror cósmico del aniquilamiento.Sólo mi madre permaneció grave, pensativa. Una arruga profunda en la cruz de las cejas revelaba su íntima, honda preocupación» (pp. 59-60).

Coirón: dureza y fragilidad EDSON FAÚNDEZ V. mientos internos y externos, anticipa tal vez la estrategia fundamental mediante la cual es factible encontrar una salida a la situación de peligro en que se encuentra la familia. La novela que leo exalta así la construcción de esos muros invisibles capaces de exorcizar las potencias hostiles a la vida.

El relato deja caer toda su luz sobre la anomalía que corregir o expulsar. Los valores del mundo gauchesco van siendo sometidos a una serie de rituales de exorcización. Las aventuras de la hombría enseñan su lado oscuro, transfigurando en hazañas despreciables; el dominio de la naturaleza deviene en depredación y pérdida de humanidad; los viajes, en nomadismo inútil; la venganza, en acto salvaje y repudiable. El relato, en este sentido, se convierte en observatorio permanente de las acciones de los personajes ${ }^{4}$, sancionando a quienes se distancian de lo axiológicamente positivo (monstruos como el Mocho) y premiando a quienes repudian «el placer inusitado de vivir» sobre la base de la supremacía del instinto (como ocurre, ya se verá, en el caso de Rafael).

La madre establece la resistencia más visible al imperio de la ley destructiva del instinto ${ }^{5}$. La burlona alusión del Zorro sobre el «monstruoso apareamiento» con las ovejas de la majada en el que interviene el Mocho, le hace proferir a ella, cuando los Arriagada y este último se han retirado, «iSalvajes!». La expresión «iSalvajes!» implica el reconocimiento de la indocilidad del otro. Una escena en la que participan José Bravo y su mujer es sugestiva en este sentido:

José Bravo chupaba los huesos, relamiéndose la boca; por las comisuras de los labios escurríanle chorros de aceite que pronto le embadurnaron el mentón, abrillantándoselo. La mujer, inclinada sobre las rodillas, comía con gula, sin alzar los ojos (p. 76-77).

Los significantes chupar, relamer, escurrir, embadurnar, abrillantar, que dan cuenta de los modos salvajes del comensal, y la inadecuada postura de la mujer, que come con gula, instalan a esta pareja de personajes entre aquéllos que son incapaces de controlar los movimientos y los apetitos del cuerpo: sujetos sin disciplina, «salvajes» a los que es necesario señalar y corregir. La micropenalidad de la escritura opera a partir de insignificantes detalles, como el acto de comer; actúa sobre la manera de gobernar los movimientos y los deseos del cuerpo, lo que hace visible y enunciable la incorrección. Los cuerpos indisciplinados son, además, cuerpos inútiles para la actuación en otro escenario que no sea el de los «horizontes sumergidos». El Zorro y el Petiso, por ejemplo, comprenden que están indisolublemente unidos al medio y que es inimaginable un destino distinto al que la pampa les tiene reservado: «somos como el coirón... La pampa nos sujeta. Para nosotros la pampa es el pasado y el presente... Y el futuro» (p. 185). Los cuerpos inútiles e indóciles de los conjurados por la pampa están al margen del poder disciplinario de las sociedades normalizadoras descritas por Michel Foucault (2000a y 200b). Su intolerable marginalidad, su anomalía, su «alteridad radical» (Baudrillard y Guillaume, 2000), se evidencia en el preciso instante en que cuando el poder construye la primitiva y oscura alma del bárbaro. Aunque el poder disciplinario y los dispositivos que lo ejecutan puedan identificarse, la novela privilegia, como ya veremos, otros caminos para soñar un porvenir distinto.

Retomo el examen de la significación de la madre. Ella añora la partida de la zona dominada por las fuerzas de la dureza. La huida de la pampa permitirá, por un lado, evitar la destrucción de la familia ${ }^{6}$, por otro, mantener viva la esperanza del hallazgo de una morada hospitalaria. Cuando se destaca este rasgo de la novela, surge la idea de que en Coirón asistimos a la narración de la decadencia de una familia chilena en la pampa argentina, como lo sostienen quienes plantean que «Belmar estudia la difícil adaptación a lugares ajenos a la propia tradición» (Montes y Orlandi, 1963, p. 228). Tal vez sería más apropiado proponer que la novela de Belmar textualiza la imposibilidad de la adaptación a un medio donde las fuerzas débiles son lo revocado.

El deseo de la madre es compartido por los miembros de la familia. El detalle del gesto de Rubén, que recoge y guarda «delicadamente en la vuelta de la boina» (39) una flor silvestre para su madre, lo sitúan en el mismo polo en el cual ella se eleva. De igual manera, Adrián, el platónico enamorado, es un personaje que comparte los códigos de la estoica y dulce mujer. En la madre, en Rubén, en Adrián (primero), en Rafael, en el padre y en Adolfo (después) lo instintivo no domina, retrocede o está en vías de retroceder. El caso de Adolfo merece atención especial, ya que en él se 
expresa con más intensidad la efervescencia instintiva: impulso cinegético, desenfreno sexual, impulso al juego, instinto homicida, dipsomanía. Adolfo es asimilado por el medio, a partir de un aprendizaje negativo ${ }^{7}$, por lo que se distancia del orden familiar; no obstante, hay indicios, como propone Gilberto Triviños, que permiten advertir un posible cambio, tales como su deseo de regresar a Chile, enunciado luego de su primer viaje, y los rasgos de sobriedad y ascetismo que surgen cuando se ha purificado «del fascinante veneno de la ciudad» ${ }^{8}$. Es, sin embargo, el otro hijo, protagonista y narrador del relato, quien se va a configurar en el eje fundamental de la tensión de las fuerzas en conflicto. Él hace, por lo tanto, posibles la observación y el examen de los detalles que singularizan las anomalías de los personajes, además de constituirse en solución ejemplar para los problemas que surgen del «placer inusitado de vivir».

He señalado que Coirón se construye sobre la base de dos territorios antitéticos e intentado mostrar sus particularidades. La singularidad de la novela de Belmar se revela, sin embargo, en el desquiciamiento del binomio civilización-barbarie. En las zonas intermedias, donde dichos dualismos colisionan, la novela adquiere su densidad significativa. Los dos territorios y sus respectivos poderes, por consiguiente, son indestructibles. La alteridad radical (la barbarie) no está por ello del todo muerta, a pesar de la serie de rituales de exorcización a los que ha sido sometido. Las siguientes citas son reveladoras en lo que respecta a la indestructibilidad de la alteridad radical:

«Cholet», el puma castrado, había perdido la poderosa esbeltez de sus formas. Una gruesa y pesada somnolencia reemplazaba su antigua gracia aniquilada bajo el diestro bisturí de Moreira, el cantor. Dormía todo el tiempo, gordo, indolente, embrutecido. Ya ni jugaba con los perros. Se había vuelto casi despreciable» (p. 174).

Mi pensamiento giraba en torno a un solo designio. Matar al Mocho. Matarlo. Sin misericordia. Sí. ¿Y cómo? Los revólveres de Adolfo ya no tenían balas. Pero en mi mente, nublada por la fiebre, empezó a insinuarse una idea confusa que, poco a poco, mientras la llanura se deslizaba fulgurante bajo los cascos desatados, fue enlazándose a imágenes precisas que se atropellaban dentro de mí. ¿Cómo darle forma al tumultoso pensamiento que me ahogaba? Mis ojos atisbaron en brevísimo instante un carancho que, lejos, se dejaba ir y venir. Súbitamente mis ideas se asociaron, y el grito me brotó, triunfal:

- iLas boleadoras! (p. 221).

El primer fragmento extrañamente no expresa ninguna complacencia ante la pérdida de la energía instintiva: «¿Por qué destruir su magnífica vitalidad? ¿ No habría otro medio, acaso, de reprimir o torcer la salvaje llamada de su instinto que comenzaba a despertar?» (p. 163). «Reprimir», «Torcer», regular, disciplinar «la salvaje llamada» del instinto para que las fuerzas de la dureza no se impongan: clave fundamental de la relación que establece la novela con el otro. Revela esto lo que el orden de los dualismos no permite advertir: la fascinación (indestructible) del narrador por la barbarie que procura expulsar. ¿El elogio del paisaje, la hospitalidad pampera $\mathrm{y}$, con más insistencia todavía, el deseo de «matar al Mocho", que emerge en el último capítulo de la novela, no testimonian notoriamente el carácter indestructible de la alteridad? Daniel Belmar no puede anular la irresistible atracción por las energías descontroladas de la barbarie. $¿$ No son acaso las mismas potencias salvajes e incontrolables de la barbarie las que se actualizan en Los túneles morados, novela que encuentra en la educación y en el aprecio por los otros pasajes liberadores? ¿Cuál es, entonces, la verdadera patria hospitalaria deseada por algunos personajes de Coirón? La dimensión en la que se despliegan las fuerzas débiles no está en Quino, tampoco en «los grupos humanos de las ciudades empapadas de envidia, de vanidad y de ambición» (p. 78). La verdadera patria (Chile) aún no existe, es una aspiración, es la utopía que se impone en un escenario donde la esperanza y el porvenir parecen abolidos.

\section{Muerte, tiempo y memoria}

Mariano Latorre, en «Carta a Daniel Belmar, novelista de Chile», advierte que Coirón es una novela en la que «predomina el medio sobre los personajes», lo que hace difícil identificar al héroe novelesco. El destacado escritor criollista concluye que la presencia del medio establece el desplazamiento y anulación de la figura del héroe:

Predomina el medio sobre los personajes, aunque éstos se distingan claramente en su eterno deambular del Neuquén a Chile y de Chile al Neuquén, tras la ola sudorosa de los rebaños.
7

Susan Suleiman (1977) señala que la novela de tesis es una novela realista que se abre al lector cargando con una enseñanza que valida o invalida una determinada doctrina. Para el cumplimiento del efecto deseado, la novela se estructura en torno a procesos de aprendizaje positivo y negativo, los cuales signan ejemplaridad. El aprendizaje ejemplar positivo es el que lleva al "héroe» a la asimilación de los valores que sustentan la novela; el aprendizaje ejemplar negativo conduce al personaje en una dirección opuesta a las conductas que el texto define de antemano como positivas.

8

Espero retomar, quizá en otro artículo, el estudio de este personaje de la novela.
Coirón: dureza y fragilidad EDSON FAÚNDEZ V. 
Es difícil, por esto, precisar al héroe en «Coirón». En mi sentir el héroe no existe (1965, p. 13).

Juan Loveluck, en «Coirón de Daniel Belmar», retoma la lectura de Latorre, asignándole al medio la condición de personaje, porque actúa como si fuera humano. La pampa se convierte así en "un elemento activo» que va «delineando el alma de los hombres que la habitan» (1951, p. 492). El verdadero héroe de Coirón, por consiguiente, es la pampa: «ella empuja a los pequeños héroes que la recorren $\mathrm{y}$ en ella viven, los determina y circunscribe a determinadas acciones. Posee la fuerza del héroe. Actúa como tal. Su inmensidad, hasta cierto punto es medicinal. Y nociva para el hombre» (1951, p. 494).

Mariano Latorre y Juan Loveluck olvidan, sin embargo, la importancia de Rafael, narrador y protagonista del relato. Rafael, que cuenta su historia personal-familiar en la pampa argentina, escribe desde un tiempo y un lugar que difieren del tiempo y del espacio textualizados. Ese otro tiempo y ese otro lugar del cual se enuncia sugieren un salto cualitativo del sujeto, que implica el acceso a una especie de soberanía sobre los instintos. La consagración del héroe requiere, sin embargo, que el lector llene el lugar vacío que se abre entre el asesinato del Mocho y el presente de la narración. Sólo así es posible imaginar los esfuerzos del héroe, que le permitieron controlar el desorden instintivo y asumir la condición de heredero de los sueños de sus hermanos muertos.

Coirón, desde esta perspectiva, puede leerse como relato de la atracción y el repudio por los deseos y acciones que dominan en «la infinita llanura hundida en los confines» (p. 105). La fascinación y el rechazo por la vida instintiva constituyen la materia misma de la confesión del narrador. Predomina por ello en la infancia de Rafael la irresistible atracción de la pampa:

La pampa se tragaba los acontecimientos. Nada persistía sobre ella. Había que vivir, y vivir olvidándose de ayer. Esperando los días, gastándolos, rompiéndolos, buscando el anhelo en el frío y silencioso corazón del tiempo (p. 58).

Pero mi infancia no reparaba en la monotonía. Poseía sus propios países, sus territorios de maravilla en donde el tiempo no existía, en donde una dorada bruma velaba la realidad y la fantasía desbocaba sus ansiosos potros de cristal.
Además, la pampa era mi patria. No conocía nada, sino la inmensidad verde y silenciosa. Nada, sino la infinita llanura hundida en los confines, y el cielo desplomando sus muros impalpables detrás de los tristes horizontes socavados (p. 99).

La monotonía de la pampa ilimitada, que convierte «al hombre en un ente primario, vegetativo, sin ambiciones ni filosofías» (p. 105), produce la sensación de la inexistencia del tiempo. La ilusión de habitar fuera del tiempo expulsa del relato de la infancia la conciencia de la finitud y el sufrimiento, a la vez que activa una fantasía desbocada que transfigura la pampa en la única patria posible. La admiración que Rafael siente por su hermano Adolfo cifra, como ya lo he señalado, la inclinación hacia lo instintivo: "yo lo admiraba. Cuando fuera grande, querría ser como él. Mi madre no podía comprenderlo, pues había huido más allá de las fronteras de su ternura» (p. 26), «admiré una vez más la apostura de mi hermano, inclinado hacia adelante para aminorar la resistencia al viento, procurando acortar la distancia que lo separaba de la avestruz» (p. 66).

Rafael es una figura fronteriza que está siendo constantemente seducida por las fuerzas de la dureza y las fuerzas de la fragilidad. La madre, «regazo de consuelo» (p. 194), despliega, así lo he sugerido, la diferencia más notoria en un contexto signado por el imperio de la «obscura violencia»: «era grato para mí sentir su suave caricia. Me invadía algo dulce. Algo tibio, un poderoso río de ternura que arrastraba mi confusa pesadumbre» (p. 145). La suavidad, la dulzura y la ternura son las fuerzas débiles que consuelan a Rafael cuando la pesadumbre lo domina; unidas crean el hilo de Ariadna, necesario para enfrentar la muerte y encontrar la salida del laberinto de los instintos. El proyecto de la madre de retornar a Chile, que termina siendo un proyecto familiar, implica la búsqueda de una salida. Adrián, el joven poeta enamorado, que funda en el regreso a Chile la esperanza de su reencuentro con Magdalena, sabe que «hay que huir de la pampa [porque]... La pampa absorbe..., destruye el pensamiento.» (p. 118). Ese saber terrible sobre la primera patria de Rafael advendrá sólo a partir de la irrupción del acontecimiento de la muerte. El asesinato de Adrián y el trágico accidente de Rubén, su «compañero dócil» (p. 132), no establecen, con todo, el triunfo de las fuerzas de la violen- 
cia y la crueldad, sino que permiten visibilizar los verdaderos rostros de las potencias oscurecidas por el despliegue de la ilusión romántica predominante en la infancia del narrador. La conciencia de la finitud y la emergencia del sufrimiento desmoronan todas las fantasías y adhesiones de la infancia, convirtiendo la «patria de ensueño y de dulzura» en un lugar peligroso. Detalles, en apariencia irrelevantes, ayudan al lector a identificar el proceso de distanciamiento del héroe novelesco: el alivio que experimenta Rafael cuando la golondrina escapa del gato; el mote de «perros» asignado a los «galancetes» de la mujer de Muerza; la captura del avestruz, signada como ejercicio cruel; la contienda-espectáculo entre el toro y el puma; el vómito que le sobreviene a Rafael después de que el indio derrotado devora «la amarillenta membrana que cubría las tripas desgarradas» (p. 95).

Huir del desorden de la pampa significa fugarse de la confusión violenta que genera el imperio de los deseos incontrolados. Implica, del mismo modo, el descubrimiento y valoración de las fuerzas de la fragilidad:

Si alguna vez algo me sugirió en forma definitiva la idea de la muerte, fue sin duda el sonido de esas espuelas sacudidas en el vacío, tañidas sin ritmo, despojadas de la pulsación vital que les imprimiera en otro tiempo la voluntad ordenadora de su dueño ahora extinguido (p. 129).

¡Ay, pequeño Rubén!... Su muerte, más que la de Adrián, significó la culminación de mi infancia. Detrás quedaron los recuerdos, los planos blancos, esa patria de ensueño y de dulzura perdida para siempre. Desde entonces, un impulso tenaz me acercó a mi madre, ansiando incorporar a mi vida sus estoicos elementos de resignación ante lo inevitable, y su poderosa facultad de lucha frente al porvenir: dulce gota de esperanza temblando en el fondo del aciago destino (p. 137).

Las escenas que clausuran la infancia del protagonista revelan problemas de máximo interés, sin los cuales parece imposible continuar reflexionando sobre la significación del repudio a las fuerzas de la dureza. La muerte de Adrián genera la disolución de la voluntad ordenadora; la muerte del pequeño Rubén, el deseo de encuentro con la madre y, por consiguiente, la exaltación de su estoicismo, ternura, capacidad de resistencia y confianza en el porvenir. La voluntad ordenadora, verdadera «pulsación vital», entra en tensión con la ausencia de voluntad característica de los personajes regidos por la pampa?.

En su aspecto tal vez más interesante la voluntad ordenadora se vincula con la memoria. Recuérdese que uno de los rasgos de la madre es su «su prodigiosa memoria [que]

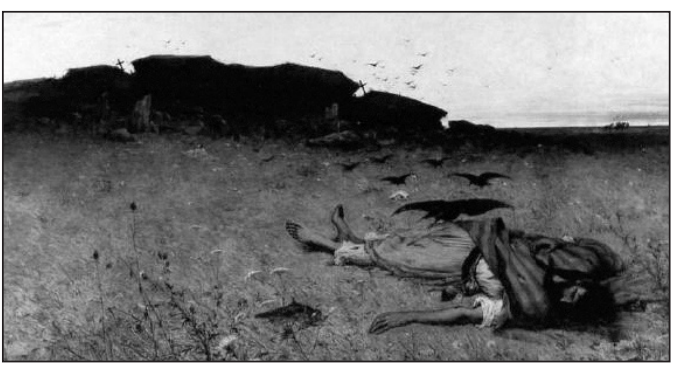

Biessy, La muerte del gaucho matrero, 1886, óleo sobre tela, Museo de la Plata, Prov. de Buenos Aires.

salvaba las lagunas que la

vida de la pampa socavara en nuestras mentes» (pp. 61-62). El deseo de encuentro con la madre, desde esta perspectiva, trae como correlato el descubrimiento de la importancia de la memoria como un arma para resistir los trabajos de la muerte y del olvido. La evocación de los hermanos muertos es significativa en lo que respecta al lugar que ocupa la memoria en la novela de Belmar:

Todo reflejaba desolación y abandono. Todo. Mas una tenue esperanza encendióse en mi corazón. Mientras yo viviera, nunca morirían mis hermanos. Nunca, el recuerdo de sus rostros, el de sus nombres. Quizás si pasados muchos años se asomaran de nuevo a la vida por las pupilas inocentes de un niño de nuestra casta, y las fuerzas perennes de sus almas encontraren, otra vez, la vasija humana en que latir... (p. 171).

El sonido de las espuelas sacudidas en el vacío marca la presencia de la muerte en los desolados y abandonados paisajes de la pam$\mathrm{pa}$, donde la hipertrofia del presente impone el olvido de los anónimos hombres que la habitan. Las vidas de los difuntos parecieran perderse hasta convertirse en coironales. La ausencia de memoria es, pues, el signo definitivo de la barbarie. Hay, sin embargo, una forma específica de resistencia contra la desmemoria y el olvido. Esa forma de resistencia se le revela a Rafael como una potencia consoladora, la que, unida a las fortalezas familiares, posibilita, por una parte, soportar el terror inherente al acontecimiento de la muerte del otro y, por otra, construir la fábula de la continuidad allí donde pareciera imponerse la pura discontinuidad de la muerte. Los hermanos muertos pervivirán en la medida en que el testigo de sus vidas recuerde sus rostros y sus nombres: «Mientras yo viviera, nunca morirían mis hermanos. Nunca, el recuerdo de sus rostros, el de sus nombres». El diálogo entre los muertos y los vivos es
9

Transcribo sólo un fragmento propuesto: "José Bravo era un cho, sin voluntad» (p. 75). que me permite ejemplificar lo hombre sin suerte, o, mejor di-
Coirón: dureza y fragilidad EDSON FAÚNDEZ V. 
tal vez el secreto que alienta en la narrativa del escritor de la Generación del 38. Jean Baudrillard, en El intercambio simbólico y la muerte, destaca como uno de los rasgos más perversos de occidente la fractura del encuentro simbólico con los muertos, quienes «no son seres protagonistas, compañeros dignos del intercambio y se los hace verlos muy bien al proscribirlos cada vez más lejos del grupo de los vivos, de la intimidad doméstica al cementerio [...], arrojados cada vez más lejos del centro hacia la periferia, y finalmente a ninguna parte, como en las ciudades nuevas o en las metrópolis contemporáneas, donde nada ha sido previsto para los muertos, que están ahí, diferentes pero vivos y compañeros de los vivos en múltiples intercambios (1992, p. 145). El narrador puede tolerar la muerte de sus hermanos y la vergüenza inmanente a su condición de superviviente mediante un compromiso ético fundamental, el cual se elucida en considerar a los difuntos como «diferentes pero vivos y compañeros de los vivos en múltiples intercambios». ¿Puede de otro modo soportar el narrador el enigma insoluble que subyace tras las elecciones realizadas por la muerte: el pequeño Rubén y Adrián? ¿No es acaso para que la muerte muera que el superviviente escucha las voces de los muertos, dibuja sus semblantes y los atesora en el cofre de la memoria? El escritor es más que el «historiador fidedigno de su tiempo», es una morada abierta a la escucha de los espectros del ayer. Transcribo un fragmento de Sonata (Carta de un adolescente):

Cuando pienso en el tiempo, recuerdo aquel surtidor cercado por el corro doliente de los sauces.

Sí. El tiempo es una parábola de cosas destruidas, una sal que se fuga, una sal amarga y ardiente que no reconstruye sus perdidos cristales. Y, sin embargo, siempre hay alguien mirándonos desde el fondo de su inexistencia, unos ojos misteriosos, radiantes.

Son los ojos de los muertos.

Su mirada tiembla, se desdibuja hasta esfumarse, y renace, exactamente como esas trémulas imágenes que se agitan, perennes, en el fondo de los ríos.

¿Cómo olvidar entonces? ¿Cómo? (Belmar, 1955, p. 35).

Esta imagen del tiempo difiere de la imagen que domina en el relato de la infancia feliz de Rafael. El tiempo no es puro presente detenido en la monotonía de la pampa; por el contrario, es «una parábola de cosas des- truidas, una sal que se fuga, una sal amarga $\mathrm{y}$ ardiente que no reconstruye sus perdidos cristales». La muerte del otro pareciera constituirse en un acontecimiento que produce la irrupción de la imagen del tiempo destructor. La pérdida de la inocencia y la dolorosa conciencia de la finitud, por lo tanto, inventan el tiempo en las ficciones novelescas de Belmar. Todo se encamina vertiginosamente hacia el desorden, la destrucción y el olvido. Esa es la terrible certidumbre que gobierna a los personajes que han experimentado el derrumbe de sus ilusiones y advertido los trabajos de la violenta y cruel realidad. Nada está, sin embargo, del todo aniquilado. Las cuencas vacías de los muertos aún tienen ojos «misteriosos, radiantes», con los que interpelan a los vivos para que asuman la responsabilidad de continuar soñando con «esas trémulas imágenes que se agitan, perennes, en el fondo de los ríos». El pensamiento ético de Emmanuel Levinas dialoga indudablemente con este aspecto de la escritura de Belmar: «el otro me individúa en la responsabilidad que tengo de él. La muerte del otro que muere me afecta en mi identidad misma de yo responsable [...] hecha de indecible responsabilidad. Es ésta mi afección por la muerte del otro, mi relación con su muerte. Ésta es, en mi relación, mi deferencia hacia alguien que ya no responde más, una culpabilidad ya -una culpabilidad de superviviente-» (cit. en Derrida, 1998, 17). La responsabilidad infinita ante el otro que muere cristaliza en memoria y escritura. Sólo de ese modo el superviviente puede tolerar la culpa y la vergüenza de continuar vivo.

El escritor que presiente la mirada de «los ojos de los muertos» y está siempre a la escucha de las imprevisibles voces del pasado, por otro lado, se convierte en heredero. Escribir es así hurgar en el cofre de la memoria, para traer otra vez a la vida las voces y los semblantes de los muertos; para responder por uno mismo, pero también por los que vivieron y vivirán; para preservar los dones legados y proyectarlos de un modo distinto al incierto porvenir. Descubrimiento fascinante que nos permite insistir en lo previamente planteado: escribir es retomar un diálogo siempre abierto con los muertos. Ese diálogo es portador de la memoria de nuestra propia fragilidad en la medida en que encierra la obligación de recibir responsablemente «lo que es más grande y más viejo y más poderoso y más duradero que [nosotros]» (Derrida, 2003, p. 13). El reco- 
nocimiento de la propia fragilidad y la aceptación del rol de legatario ${ }^{10}$ hacen posibles la comunión con las fuerzas débiles y la fábula del futuro. No hay conocimiento, ni medios de orientación posibles, sin el diálogo misterioso con los difuntos, sin la certidumbre de la propia finitud y sin la transfiguración del escritor legatario en sujeto infinitamente responsable ante los muertos.

Ha aumentado, es cierto, el número de volúmenes de la biblioteca universal, mediante la fiebre revisionista y los adelantos de la tecnociencia, pero no ha aumentado el número de herederos. El incremento de las posibilidades de acceso a la información no ha generado la recuperación del tiempo perdido y la reactivación de la memoria. La confianza en el progreso y en el futuro hace mucho ha caído en descrédito y la acumulación de conocimiento ha contribuido a generar «nueva barbarie, neoanalfabetismo y empobrecimiento del lenguaje, nueva pobreza, implacable reconfiguración de la opinión por los medios de comunicación, un espíritu condenado a la miseria y un alma al desuso, cosa que Walter Benjamín y Theodor Adorno no dejaron de destacar» (Lyotard, 1998, p. 70). Algo calla y espera aún en el relato que ha sido leído, entre otras posibilidades, como novela de la tierra (Loveluck, 1951), novela de «los grandes espacios americanos» (Coloane, cit en Martínez, 2009, 82), «novela de frontera» (Varas, 2009, p. 166), novela del exilio y de la decadencia de una familia (Montes y Orlandi, 1963). Tal vez el estudio de las relaciones profundas e inextricables que se establecen entre escritura, muerte y memoria puedan contribuir a interpretar de un modo distinto la obra del escritor que continúa resistiendo el orden aún vigente en el mundo, donde se impone el olvido y la desmemoria.

La estrategia utilizada por Adrián para no olvidar el pasado es la escritura; de esa manera, «trató inconscientemente de aferrarse al pasado, y preservarlo del olvido». Así pervive, en Coirón, el sueño del amor. No hace otra cosa Daniel Belmar: escribe para mantener vivo el amor. Su escritura es por ello un refugio similar al «tibio refugio» de la casa familiar evocada en Coirón. Pero también es el espacio de la memoria, de la responsabilidad ante los difuntos, del heredero, del viaje hacia el encuentro con el otro, de la resistencia a las fuerzas hostiles a la vida y de la «quimera del porvenir». Morada hos- pitalaria que opone a la dureza del mundo su fragilidad.

\section{Bibliografía}

Baudrillard, Jean (1992), El intercambio simbólico y la muerte, Caracas, Monte Ávila Editores Latinoamericana.

Baudrillard, J. y Guillaume, M. (2000), Figuras de la alteridad, México, Taurus.

Belmar, Daniel (1953), Coirón (Tierra de los borizontes sumergidos), Santiago de Chile, Zig-Zag.

- (1955), Sonata (Carta de una adolescente), Santiago de Chile, Zig-Zag.

- (1963), Los túneles morados, Santiago de Chile, Zig-Zag.

Bloch, Ernst (2004), El principio esperanza, Madrid, Trota.

Canetti, Elías (1994), La conciencia de las palabras, México, D. F., Fondo de Cultura Económica.

Derrida, J. y Roudinesco, E. (2003). Y mañana qué..., México D.F., Fondo de Cultura Económica.

Foucault, Michel (2000a), Defender la Sociedad, Buenos Aires, Fondo de Cultura Económica de Argentina S. A.

- (2000b), Vigilar y Castigar, Madrid, Siglo Veintiuno de España Editores.

Henríquez Ureña, Pedro (1954), Las Corrientes Literarias en la América Hispánica, México, Fondo de Cultura Económica.

Latorre, Mariano (1965), «Carta a Daniel Belmar, Novelista de Chile», en Daniel Belmar, Coirón, Santiago de Chile, Zig-Zag.

Lefebvre, Alfredo (1963), «Prólogo», en Daniel Belmar, Los túneles morados, Santiago de Chile, Zig-Zag.

Loveluck, Juan (1951), «Coirón de Daniel Belmar», en Atenea: 312, pp. 490-497.

Lyotard, Jean François (1998), Lo inbumano. Charlas sobre el tiempo, Buenos Aires, Manantial.

Martínez Elissetche, Pacián (2009), Daniel Belmar: rescate y memoria, Concepción, Artistas del Acero.

Montes y Orlando (1963), Historia y Antología de la Literatura Chilena, Santiago de Chile, Editorial del Pacífico.

Sarmiento, Domingo Faustino (1993), «Conflicto y Armonía de las Razas en América», en Leopoldo Zea (compilador), Fuentes de la Cultura latinoamericana, México D.F., Fondo de Cultura Económica.
10

Resulta ineficaz rememorar, ordenar y archivar el pasado; también guardarle una pasmosa y servil lealtad. El heredero, advierte Derrida (2003), es siempre fiel e infiel a la herencia recibida. No habrá recuperación (activa) del pasado sin desplazar, interpretar y criticar la herencia. Escribir ficciones tiene que ver sin duda, con dicha forma de recuperación.
Coirón: dureza y fragilidad EDSON FAÚNDEZ V. 
Suleiman, Susan (1977), «Le Récit Examplaire», en Poétique, no 37.

Triviños, Gilberto (s/f), «Notas inéditas».

Varas, José Miguel (2009), «Los escritores chilenos olvidados son muchos» (entrevis- ta), en Pacián Martínez Elissetche, Daniel Belmar: rescate y memoria, Concepción, Artistas del Acero.

Fecha de recepción: 21/07/2011

Fecha de aprobación: 22/10/2011 